\title{
Costs of Perico (Coryphaena Hippurus) freezing for the improvement of the quality of life of artisanal fishermen in Peru
}

\author{
Juan José Milón Guzmán ${ }^{1, *}$, Sergio Leal Braga ${ }^{2}$, Herbert Jesús del Carpio Beltrán ${ }^{1}$, Mario Enrique Díaz Coa ${ }^{1}$ \\ ${ }^{1}$ Universidad Tecnológica del Perú, Peru \\ ${ }^{2}$ Pontifícia Universidade Católica do Rio de Janeiro, Brazil
}

\begin{abstract}
An experimental study was carried out to determine the costs of freezing artisanally fished Perico (Coryphaena Hippurus) in Peru. A refrigeration chamber was equipped with electrical and temperature sensors to determine the thermal efficiency and thus calculate the costs of freezing the fish. The results indicate that it is possible to freeze and store fish to avoid speculation due to over production and thus improve the selling prices. In this way, it is possible to store the fish until the prices are attractive again so that fishermen sell their product at fair prices and progressively improve their quality of life.
\end{abstract}

\section{Introduction}

Artisanal fishing is a small-scale economic activity that takes place throughout the world by populations that live near the coast. This economic activity is usually characterized by a reduced use of technologies and a reduced degree of organization of the fishing process [1] In Latin America, this activity is performed for subsistence, shaping the culture of the communities that practice it. Some communities that used to fish have disappeared because they could not compete with largescale fishing prices [2], causing an invaluable loss of culture and triggering the launch of protection measures by current governments that aim at achieving a sustainable exploitation of marine resources and the integration of artisanal fishermen into the economic ecosystem [3].

One of the main maritime resources extracted by artisanal fishing is Perico (Coryphaena Hippurus), which is one of the most exported fish, with an average annual catch of 52 thousand tons. Perico is abundant during the summer, which causes a great percentage of fishermen to fish it illegally. By doing this, they affect the traceability of marine products that reach the market. Fortunately, with the appearance of unions and organizations of artisanal fishermen, inclusion of fishermen in the legal system is facilitated.

Perico extraction occurs mainly in Paita and Matarani ports [4]. An important problem of this activity is the sale price of the product to intermediaries: since illegal actors are present in the market, the purchase price is well below the right commercialization price, forcing in certain circumstances fishermen to sell without recovering their investment. Different alternatives have been proposed to improve this situation and one of them is freezing and preserving Perico at low temperatures until the sale price is appropriate for the fishermen. Previous studies have found that the cost of conservation of hydrobiological products at low temperatures to keep products in better conditions and give them added value for commercialization would exceed 726000 soles (203000 USD or 173000 EUR) [5] [6] [7].

\subsection{Price regulation in artisanal fishing}

Artisanal fishing in Peru takes place along the entire coastline. The vessels used have a maximum capacity of 7 tons and, for Perico, fishing takes up to 15 days to guarantee a return on investment [8] [9]. Perico can generally be extracted from October to March. This seasonality causes the fishermen to collect the product in this period at approximately 150 miles from the coast. Perico is marketed mainly for the preparation of a Peruvian typical dish called "ceviche", which is why it is highly requested by restaurants and hotels. The price of Perico at the port ranges between $0.5 \mathrm{USD} / \mathrm{kg}$ and 1.5 $\mathrm{USD} / \mathrm{kg}$. This value is determined by the commercial entrepreneurs who force fishermen to accept a negotiated price at the time the boat arrives at port. Fishermen do not have many sale opportunities and options so they must accept the prices established by the merchant. The profit of the trader in this transaction ranges between $300 \%$ and $400 \%$ [4] [10] [11].

\section{Experimental Model}

The experimental model is made up of the refrigeration chamber and the measurement and acquisition system (Fig. 1).

* Corresponding author: jmilon@utp.edu.pe 


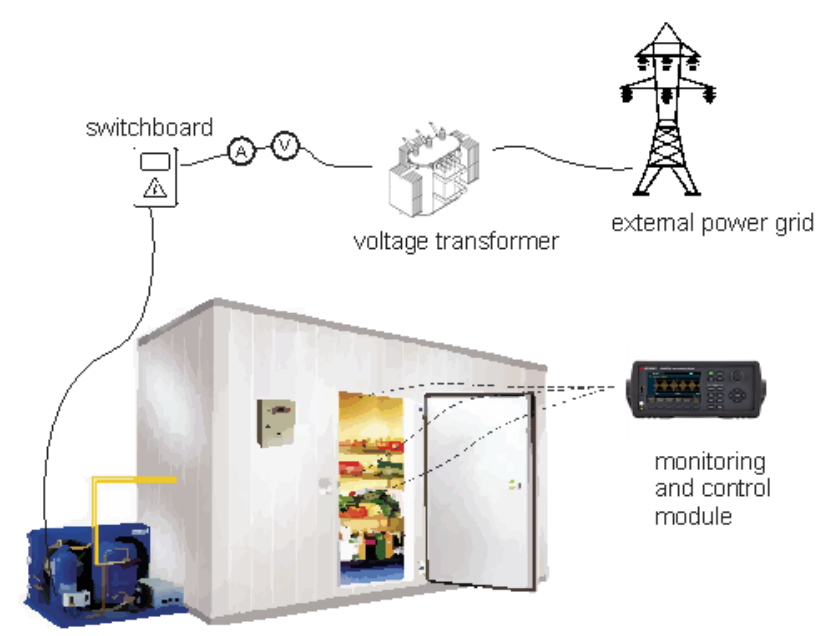

Refrigeration chamber

Fig. 1. Experimental Model diagram.

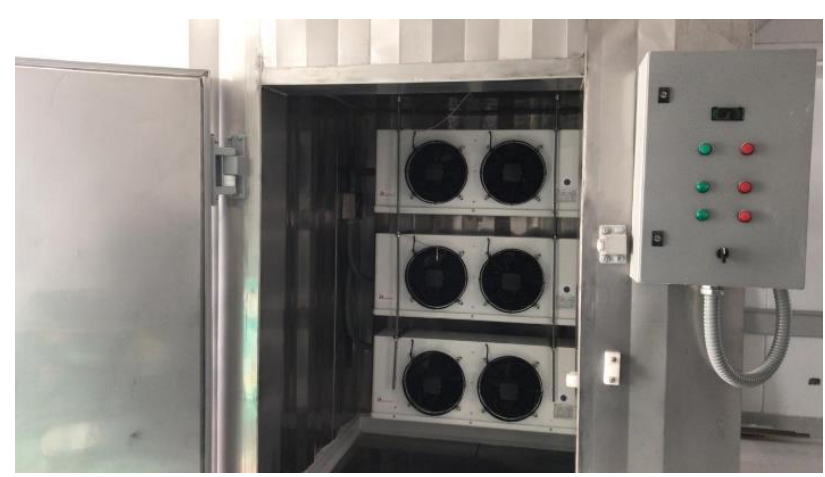

Fig. 2. Experimental Model picture.

The refrigeration chamber was made of stainless steel with a 5"-thick expanded polyurethane thermal insulation. This prototype had a volume of $9 \mathrm{~m}^{3}$, with a maximum capacity for $1000 \mathrm{~kg}$ of fish. It had a $6 \mathrm{~kW}$ vapor compression refrigeration system. K-type thermocouples were installed on the thermal load and inside the chamber. To monitor power, electrical sensors were installed (for power, current and voltage measurement). The studied uncertainties are shown in Table 1.

Table 1. Measurement uncertainties.

\begin{tabular}{|l|c|c|}
\hline Parameters & $\begin{array}{c}\text { Uncertainty, } \\
\%\end{array}$ & Reference \\
\hline $\begin{array}{l}\text { Electrical } \\
\text { current }\end{array}$ & 0.5 & Instrument \\
\hline Voltage & 0.1 & Instrument \\
\hline Temperature & 2.5 & Instrument \\
\hline $\begin{array}{l}\text { Electrical } \\
\text { power }\end{array}$ & 0.5 & {$\left[\left(\frac{\delta \mathrm{I}_{\mathrm{PV}}}{\mathrm{I}_{\mathrm{PV}}}\right)^{2}+\left(\frac{\delta \mathrm{V}_{\mathrm{PV}}}{\mathrm{V}_{\mathrm{PV}}}\right)^{2}\right]^{0.5}$} \\
\hline
\end{tabular}

\section{Results and analysis}

Figure 3 shows the variation of the temperature as a function of the duration of the experiment. Two types of thermal loads were installed inside the chamber: 7 units of 4-kg loads and 6 units of $20-\mathrm{kg}$ loads, making a total $160-\mathrm{kg}$ heat load. The $4-\mathrm{kg}$ load took 9 hours to change phase and the 20-kg load took 13 hours. The air temperature inside the chamber ranged from $-28^{\circ} \mathrm{C}$ to $20^{\circ} \mathrm{C}$. The spikes in air temperature are due to the evaporator defrosting system.

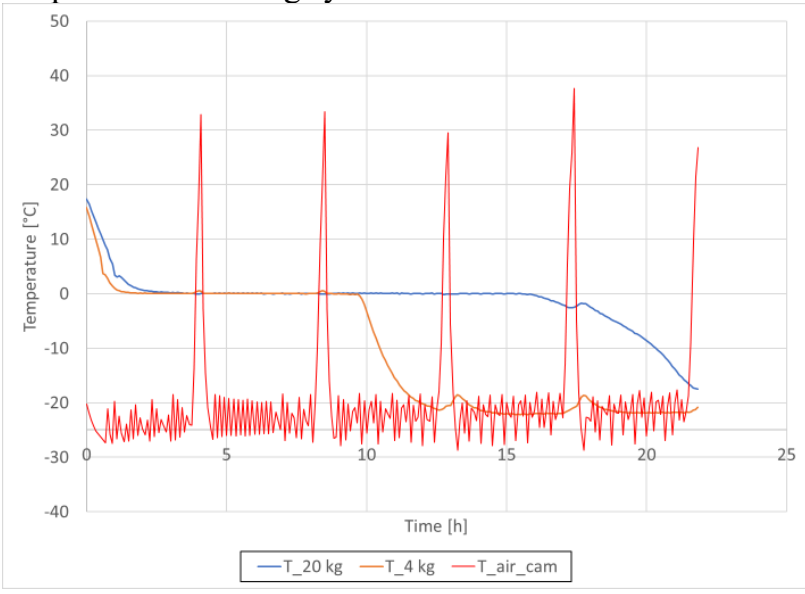

Fig. 3. Thermal parameters.

Figure 4 shows the variation of the electrical power over time. The values range between $500 \mathrm{~W}$ and $7000 \mathrm{~W}$. The electrical power was also affected by the start-up of the condensing units. During the 24 hours-period. the system was turned on 5 times.

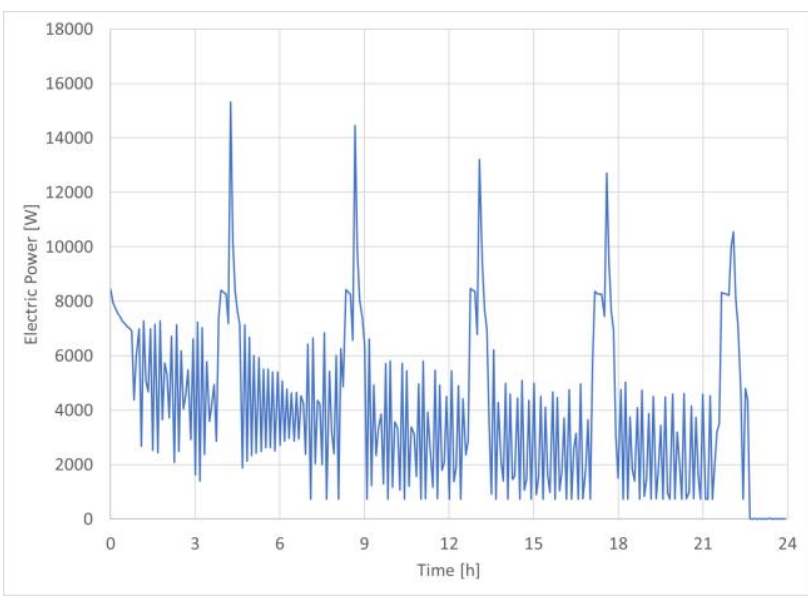

Fig. 4. Electric power.

Figure 5 shows the variation of power (electric and thermal) and thermal efficiency for different time intervals. These time intervals are defined as a function of the thermal load (phase change begins), that is, with the start and the end of the phase change according to the mass of the thermal load (4 kg and $20 \mathrm{~kg}$ ). Although it has not been possible to determine the Coefficient of Performance (COP) of the cooling system, the thermal efficiency results are shown, that is, the relationship between the energy loss of the thermal load and the electrical power supplied. This efficiency ranges from $20 \%$ to $40 \%$.

Figure 6 shows the variation in thermal insulation losses as a function of time. The refrigeration chamber loses between 80 and $100 \mathrm{~W}$ in the process of freezing the thermal load. The greater the difference in temperature between the interior and exterior of the camera, the greater the loss. In the calculation of losses, the opening of the 
door for product renewal has not been considered, because the storage is in batches that are kept behind closed doors until the moment of sale.

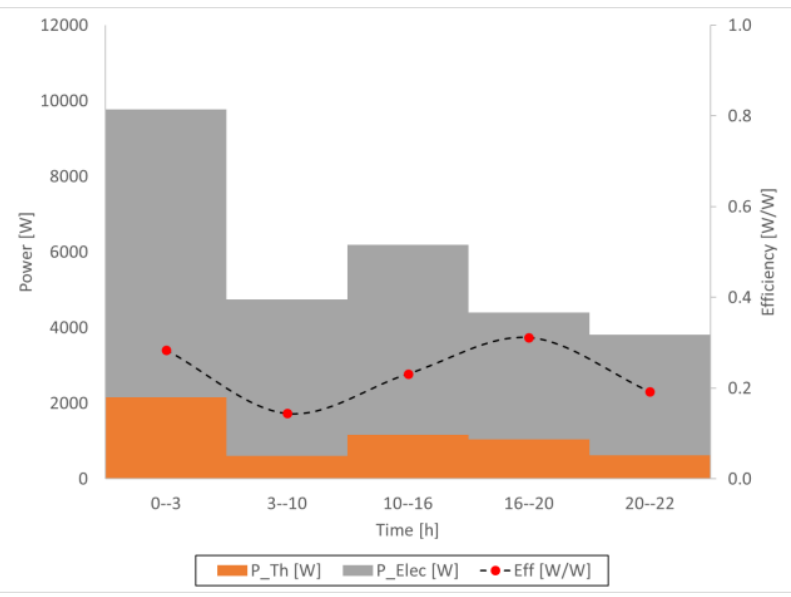

Fig. 5. Thermal efficiency.

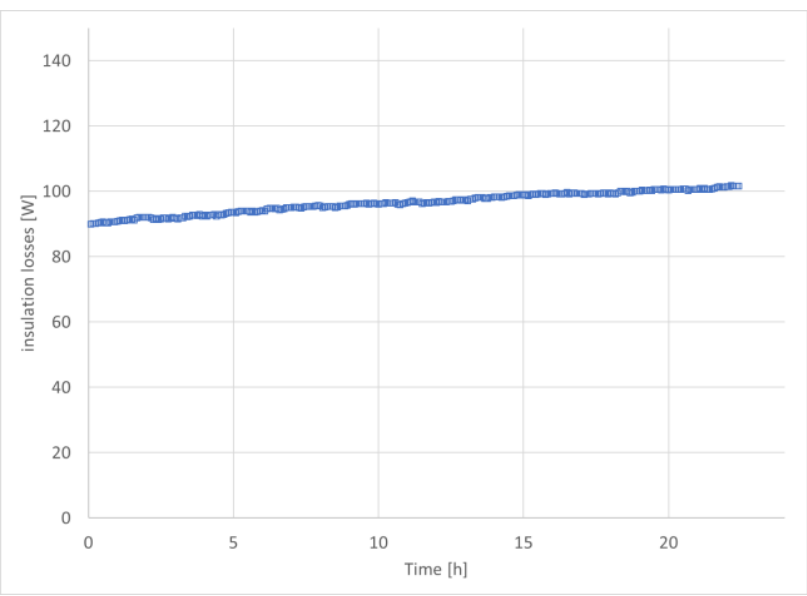

Fig. 6. Thermal efficiency.

Figure 7 shows the variation of the temperature of the thermal load inside the chamber and the evolution of the cost of freezing with time. As observed, the electrical control system disconnects the power supply at $-18^{\circ} \mathrm{C}$ and, due to insulation losses, the temperature rises. The control system is programmed to turn on at $-16{ }^{\circ} \mathrm{C}$. With these considerations, the costs of freezing $(0.37 \mathrm{USD} / \mathrm{kg})$ and daily storage $(0.013 \mathrm{USD} / \mathrm{kg})$ can be estimated. In the Figure, time equal to 0 is the moment at which the fish is frozen at $-18^{\circ} \mathrm{C}$.

Figure 8 shows the fish selling prices at the arrival to the port and in the market (2019). The difference between both is the amount that the dealer earns when purchasing directly from the fisherman and selling the product in the market. Perico fishing is performed only from October to March, thus due to an excessive supply during this period, the selling prices at the port are low. Hence, when artisanal fishing production begins to decrease, prices rise. To take advantage of this situation, fishermen could use refrigeration chambers to store the fish. The appropriate time to sell the product could be determined based on the freezing and storage costs.

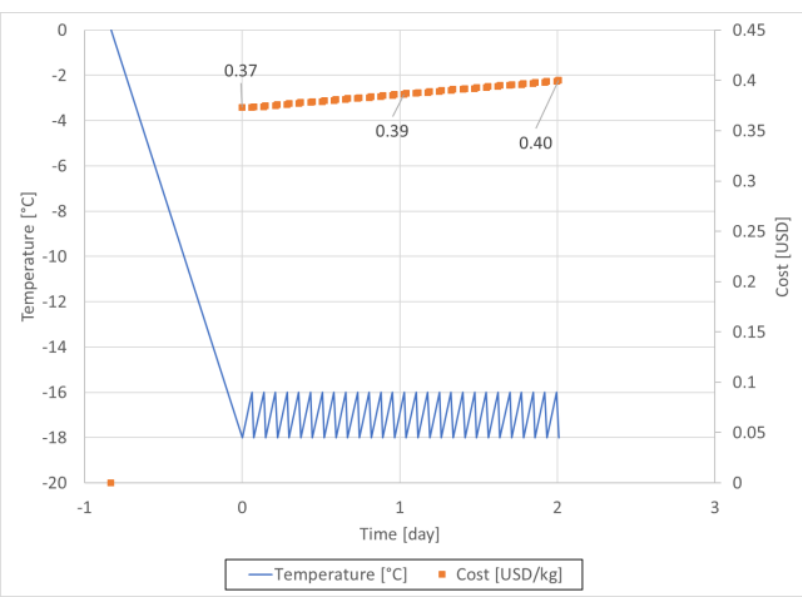

Fig. 7. Evolution of thermal load temperature and cost with time.

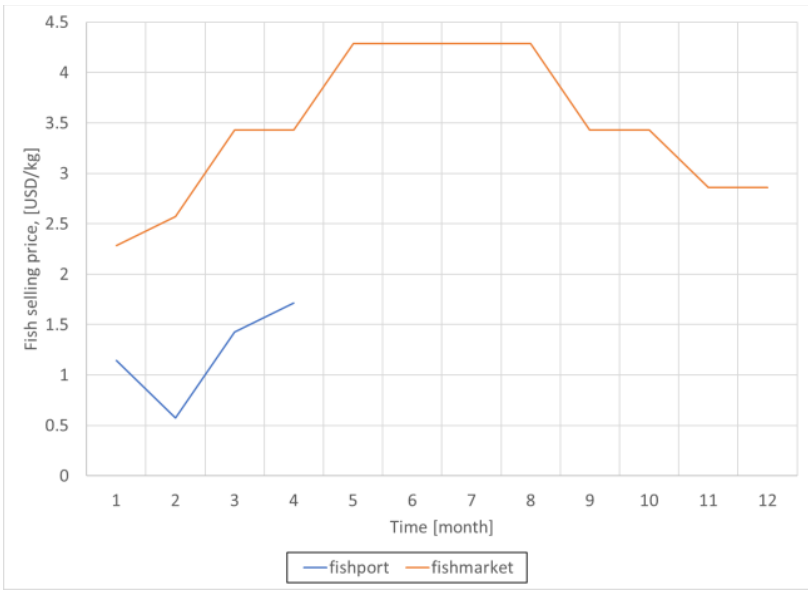

Fig. 8. Selling prices variation for 2019.

\section{Conclusions}

The cost of artisanal fished Perico (Coryphaena Hippurus) freezing and storing was determined. This data could help fishermen to consider investing on a refrigeration chamber so that they can freeze the fish and avoid selling when prices are very low and doing it when the price is fair, depending on the freezing costs and the availability of the product in the market. It is important to emphasize that today fishermen sell their fish in the port, paying the people that operate the boat with fish. The fishermen culture leaves little place for change, including the possibility of associating to control the selling price of Perico. It was observed that the main beneficiary in the commercialization process is the dealer who buys the fish at the port and sells it to local markets. It is currently difficult to make fishermen understand the need and the benefits of added value, making it difficult to promote the creation of fishing associations for business reasons, even if in this way fishermen themselves can become dealers and sell their products in the city markets.

Business initiatives for market expansion should also be considered. The transport and sale of Perico in markets in the nearest cities triple profits, in the long term the opening of restaurants "from sea to table" is an unavoidable added value option. 


\section{References}

1. FAO, "The state of wold fisheries and aquaculture," FAO, Roma, 2000.

2. H. Robotham, E. Bustos, F. Ther-Rios, M. Avila, M. Robotham, C. Hidalgo and J. Muñoz, "Contribution to the study of sustainability of small-scale artisanal fisheries in Chile," Universidad Diego Portales, Santiago de Chile, 2019.

3. T. A. Caamaño Muñoz, L. C. Castro Bastías, A. E. Moreno Recabal and M. C. Rodríguez Pérez, "El rescate del oficio De la pesca artesanal como ocupación colectiva y su relevancia en la Localidad de caleta Tumbes," Universidad Andrés Bello, Concepción, 2017.

4. T. E. Suarez Yana, "Sostenibilidad de la pesca artesanal del perico (Coryphaena hippurus): El caso de las cooperativas pesqueras en el Perú," Pontificia Universidad Católica del Perú, Lima, 2019.

5. D. Vásquez Parrilla, "Diseño de cámara frigorífica de 1500 toneladas de capacidad para conservar productos hidrobiologicos congelados a una temperatura de $-20^{\circ} \mathrm{c}$ en la empresa ARCOPA S.A," Universidad Nacional de Piura, Paita, 2018.
6. W. Guzmán Ortiz, "Diseño de planta piloto de refrigeración industrial y de estrategia de control," Universidad de Piura, Paita, 2018.

7. A. R. Villacís Pérez, "Análisis y diseño de un sistema de refrigeración por absorción," Universidad San Francisco de Quito, Quito, 2011.

8. S. Corral and D. Romero Manrique de Lara, "Participatory artisanal fisheries management in islands: Application to the Canary Islands," Universidad de La Laguna, Guajara, 2017.

9. C. Zelada M., J. Estupiñan N., L. Marcelo R., A. Cárdenas C. and M. Bendezú R., "Impacto de la pesca artesanal y el empleo en el puerto de huacho 2001-2011," Universidad Nacional José Fautino Sanchez Carrión, Huacho, 2011.

10. M. M. Oha Cahui and S. R. Soto Calachua, "Pesca artesanal marítima y su aprovechamiento para una propuesta de turismo marinero, en el distrito de Islay Matarani," Universidad nacional de San Agustín de Arequipa, Arequipa, 2018.

11. FAO, "La pesquería del perico (Coryphaena hippurus) en el Perú: caracterización y análisis de la cadena productiva," FAO, Lima, 2015. 